\title{
PROGNOSIS OF COMPLETELY RESECTED PN2 NON-SMALL CELL LUNG CARCINOMAS: WHAT IS THE SIGNIFICANT NODE THAT AFFECTS SURVIVAL?
}

Morihito Okada, MD

Noriaki Tsubota, MD

Masahiro Yoshimura, MD,

Yoshifumi Miyamoto, MD

Hidehito Matsuoka, MD
Objective: We analyzed the effect of the station of mediastinal metastasis with regard to the location of the primary tumor on the prognosis in patients with non-small cell lung cancer. Methods: Of 956 consecutive patients who underwent operation for primary lung carcinoma between 1986 and 1996,760 patients $(\mathbf{7 9 . 5 \%})$ were diagnosed as having nonsmall cell carcinoma and were subjected to complete removal of hilar and mediastinal lymph nodes together with the primary tumor. Results: The status of lymph node involvement was $\mathrm{NO}$ in 480 patients $(63.2 \%)$, $\mathrm{N} 1$ in 139 patients $(\mathbf{1 8 . 3 \%})$, and $\mathrm{N} 2$ in 141 patients $(\mathbf{1 8 . 6 \%})$. The 5- and 10-year survival of patients with $\mathrm{N} 2$ disease were $26 \%$ and $17 \%$, respectively. Neither cell type nor the extent of procedure was a significant survival determinant. Patients having involvement of subcarinal nodes from upper-lobe tumors had a significantly worse prognosis than those patients with metastases only to the upper mediastinal or aortic nodes $(P=.003)$. Patients with nodal involvement of the upper mediastinum from lower-lobe tumors had a significantly worse survival than those patients with metastases limited to the lower mediastinum $(P=.039)$. Furthermore, patients with involvement of the aortic nodes alone from left upper-lobe tumors had a significantly better survival than those patients with metastasis to the upper or lower mediastinum beyond the aortic region $(P=\mathbf{0 4 4})$. Conclusions: When mediastinal metastasis is limited to upper nodes from upper-lobe tumor, to lower nodes from lowerlobe tumor, or to aortic nodes from left upper-lobe tumor, acceptable survival could be expected after radical resection. (J Thorac Cardiovasc Surg 1999;118:270-5)
$A^{\prime}$ lthough resection for non-small cell lung cancer remains the management of choice whenever possible, considerable controversy still exists on interpretation of the prognostic and therapeutic implications of metastases to ipsilateral mediastinal node (N2) disease. Many physicians believe in their inability to control N2 disease by surgical treatment and regard it as a contraindication to thoracotomy, but some of these lesions demonstrate relatively fine prognosis after complete resection. ${ }^{1,2}$ Varying survival associated with the surgical treatment of

From the Department of Thoracic Surgery, Hyogo Medical Center for Adults, Akashi City, Hyogo, Japan.

Received for publication Sept 15, 1998; revisions requested Dec 3, 1998; revisions received April 2, 1999; accepted for publication April 2, 1999.

Address for reprints: Noriaki Tsubota, MD, Department of Thoracic Surgery, Hyogo Medical Center for Adults, Kitaohji-cho 13-70, Akashi City 673, Hyogo, Japan.

Copyright (C) 1999 by Mosby, Inc.

$0022-5223 / 99 \$ 8.00+0 \quad \mathbf{1 2 / 1 / 9 9 0 9 7}$
$\mathrm{N} 2$ disease may be due to differences in the extent and level of metastatic nodes. The station of mediastinal lymph node metastases has not been considered as a prognostic indicator for survival in most publications. Naruke and colleagues ${ }^{3}$ reported that the prognosis of patients with subcarinal lymph node metastases was lower than that of patients with metastases to lymph nodes in other mediastinal locations after surgical resection, which was not confirmed by Martini and colleagues. ${ }^{4}$ Thus a few studies have evaluated the effect of metastatic spread on the survival of patients with lung cancer, but the results have been controversial and confusing.

We reviewed the clinical records of patients with non-small cell lung cancer, all of whom had been subjected to complete resection of tumors with complete mediastinal dissection. The purposes of this study were to analyze the relationship among the station of mediastinal metastases, to analyze the location of the primary tumor and the overall survival rate, and to understand significant nodes that affect postoperative survival. 
Table I. Relationship between the location of primary tumor and pathologic $N$ factor

\begin{tabular}{lrrrrrr}
\hline & \multicolumn{5}{c}{ Location of tumor $(n)$} & \\
\cline { 2 - 5 }$N$ factor & Rt- $U$ & Rt- $M$ & Rt- $L$ & Lt- $U$ & Lt- $L$ & Total $(n)$ \\
\hline pN0 & 135 & 38 & 92 & 126 & 89 & 480 \\
pN1 & 38 & 29 & 18 & 29 & 25 & 139 \\
pN2 & 48 & 16 & 22 & 30 & 25 & 141 \\
Total & 221 & 83 & 132 & 185 & 139 & 760
\end{tabular}

$R t-U$, Right upper lobe; $R t-M$, right middle lobe; $R t-L$, right lower lobe; $L t-U$, left upper lobe; $L t-L$, left lower lobe.

\section{Patients and methods}

Between January 1986 and December 1996, 956 consecutive patients underwent operation for primary lung cancer by the same surgical team. Of these, 760 patients $(79.5 \%)$ with proven non-small cell carcinoma underwent curative operation, which was defined as complete removal of ipsilateral hilar and mediastinal lymph nodes together with the primary tumor. There were 568 men and 192 women with a mean age of 63 years (range, 30-88 years). Patients who had evidence of residual tumor at the surgical margin, malignant effusion, or N3 disease (verified by intraoperative findings or postoperative pathologic examination) were defined as noncurative operation and were excluded from this study. Tumors with minute satellite nodules that were found incidentally within the same lobe of the resected specimen were not excluded from this study because we were not certain whether these lesions should be considered local tumor spread or not. Tumors with satellite lesions in another lobe were excluded. Resected specimens were examined histopathologically, and histologic typing was done according to the World Health Organization classification. ${ }^{5}$ Patients whose tumors were subsequently classified as small cell carcinoma or low-grade malignant tumor were also excluded. Surgical-pathologic staging was assigned according to the New International Staging System for Lung Cancer. ${ }^{6}$ The lymph node classification schema that has been recommended by the American Joint Committee on Cancer and adapted from Naruke and colleagues $^{3}$ was used to designate $\mathrm{N}$ disease.

Routine systematic dissection of all the hilar and mediastinal nodes was performed in every case, even if the preoperative evaluation was N0 or N1. Every node dissected en bloc (not sampled) was placed into the compartments, with each lymph node level numbered separately during the operation, and was examined by pathologists to be diagnosed as microscopically positive or negative after the operation. The sites of N2 lymph nodes were divided into upper mediastinal (highest mediastinal nodes, paratracheal nodes, pretracheal nodes, anterior mediastinal nodes, posterior mediastinal nodes, and tracheobronchial angle nodes), aortic (Botallo's nodes, paraaortic nodes, and ascending aortic nodes), and lower mediastinal (subcarinal nodes, paraesophageal nodes, and pulmonary ligament nodes) lymph nodes. ${ }^{3,4}$ Operative mortality rates implied a 30-day postoperative mortality plus intraoper-

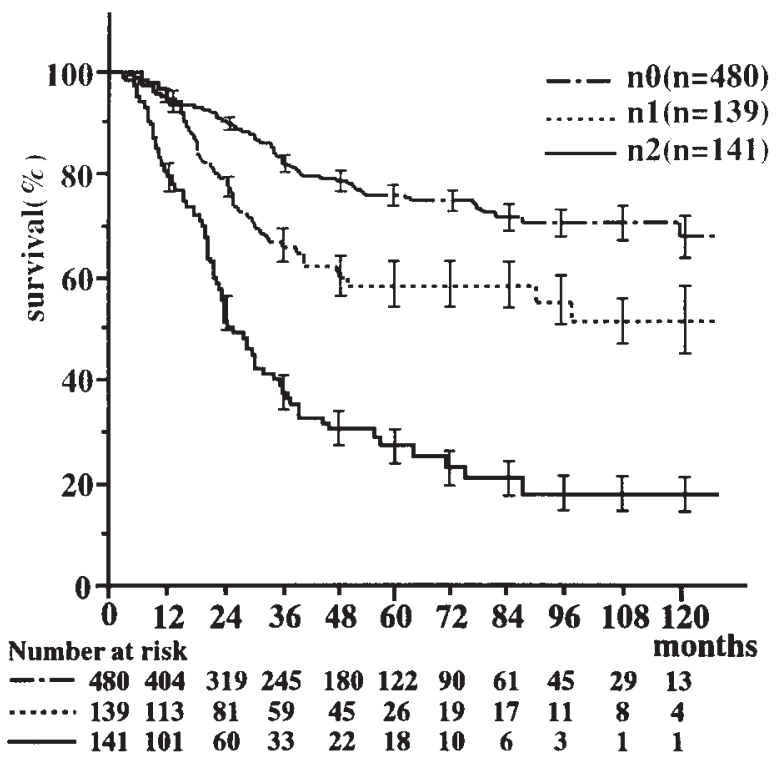

Fig 1. Cumulative survival curves of patients who underwent complete resection for non-small cell lung cancer according to surgical-pathologic status of ipsilateral mediastinal lymph nodes. Patients with NO disease had a significantly better survival than those patients with $\mathrm{N} 1$ disease $(P=.0009)$, and patients with $\mathrm{N} 1$ disease had a significantly better survival than those patients with $\mathrm{N} 2$ disease $(P=.0001)$.

ative mortality. Survival was estimated by the Kaplan-Meier method, ${ }^{7}$ and differences in survival were determined by logrank analysis. A multivariate analysis of various independent prognostic factors was assessed by Cox's proportional hazards regression model. ${ }^{8}$ Zero time was the date of pulmonary resection, and the terminal event was death attributable to cancer, noncancer, or unknown cause. Operative death was included.

\section{Results}

Overall follow-up ranged from 18 to 150 months, with a median of 61 months. The operative mortality rate was $0.3 \%$ ( $2 / 760$ patients). One patient died of hemorrhage during completion pneumonectomy. The cause of death in the remaining patient was acute myocardial infarction. The relationship between the location of the primary tumor and the pathologic $\mathrm{N}$ factor is shown in Table I. The status of lymph node involvement was N0 in 480 of the 760 patients (63.2\%), N1 in 139 patients (18.3\%), and N2 in 141 patients $(18.5 \%)$. A significant difference in survival according to the absence or presence of N1 or N2 nodes is shown in Fig 1. The 5-year survival of patients with N0, N1, and N2 disease was $77 \%, 58 \%$, and $26 \%$, respectively (N0 vs N1, $P=.0009 ;$ N1 vs N2, $P=$ 


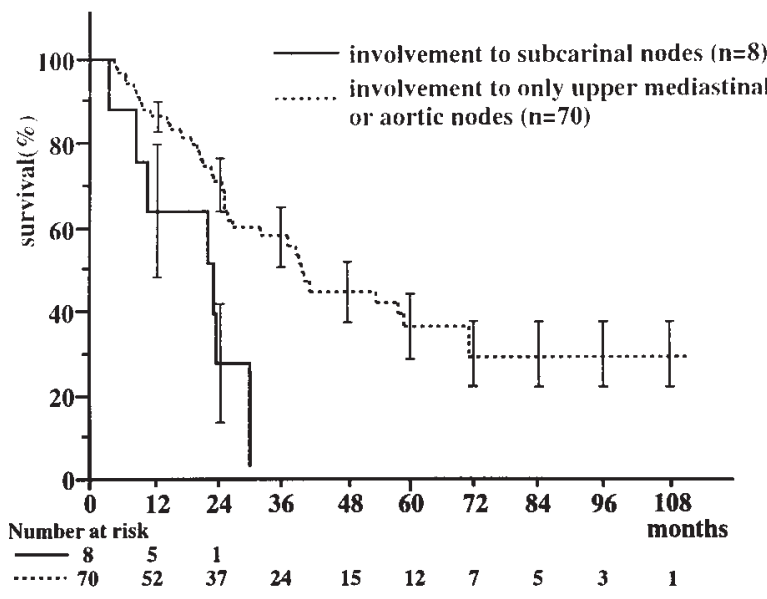

Fig 2. Cumulative survival curves of patients with an upperlobe tumor according to the absence or presence of subcarinal node metastases. Patients having involvement of subcarinal nodes had a significantly worse prognosis than those patients with metastasis only to the upper mediastinal or aortic nodes $(P=.003)$.

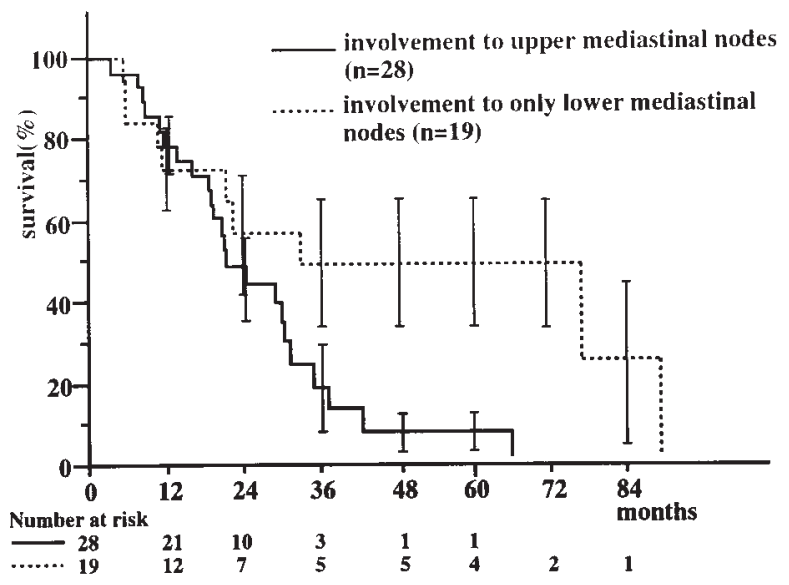

Fig 3. Cumulative survival curves of patients with a lowerlobe tumor according to the absence or presence of upper mediastinal metastases. Patients with nodal involvement of the upper mediastinum had a significantly worse survival than those patients with metastasis only to the lower mediastinum $(P=.039)$.

$.0001)$. In addition, $70 \%$ of patients with N0 disease, $52 \%$ of patients with $\mathrm{N} 1$ disease, and $17 \%$ of patients with $\mathrm{N} 2$ disease were expected to survive 10 years or more after operation.

In the 141 patients with $\mathrm{N} 2$ disease, the histologic cell types were 98 adenocarcinoma, 40 squamous cell carcinoma, 2 adenosquamous carcinoma, and 1 large cell carcinoma. Histologic classification was not a sig-

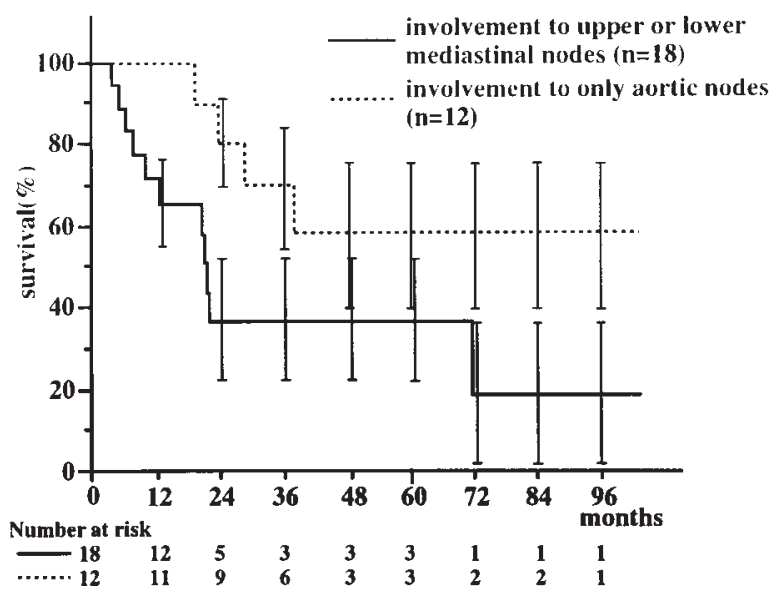

Fig 4. Cumulative survival curves of patients with a left upper-lobe tumor according to the absence or presence of aortic node metastases. Patients with involvement of only the aortic nodes had a significantly better survival than those patients with metastasis to the upper or lower mediastinum over the aortic region $(P=.044)$.

nificant survival determinant (adenocarcinoma versus squamous cell carcinoma, $P=.76$ ). Lobectomy was by far the most common procedure and was performed in 123 patients, including 21 combined sleeve resections of the bronchus. Fourteen pneumonectomies including 2 sleeve techniques for the tracheobronchus and 4 segmentectomies were performed. Because we followed the policy that lung-saving procedures such as bronchoplasty must always be kept in mind, ${ }^{9}$ we performed very few pneumonectomy procedures. The extent of procedure did not significantly affect survival (lobectomy versus pneumonectomy, $P=.98$ ).

The locations and levels of involved nodes affected survival. Patients having involvement of subcarinal nodes from either right or left upper-lobe tumors $(\mathrm{n}=8)$ were not expected to survive 3 years after operation and had a significantly worse prognosis than those patients with metastases only to the upper mediastinal or aortic nodes (n $=70 ; P=.003)$. The 5-year survival for these patients was $0 \%$ and $37 \%$, respectively (Fig 2). Table II shows a multivariate analysis of independent prognostic factors among patients with an upper-lobe tumor. Involvement of subcarinal nodes was a statistically significant factor $(P=.023)$. On the other hand, patients with nodal involvement of the upper mediastinum from either right or left lower-lobe tumors $(n=28)$ had a significantly worse survival than those with metastases limited to the lower mediastinum ( $\mathrm{n}=19 ; P=.039$ ). The survival in these patients was $8 \%$ and $49 \%$ at 5 years, respectively (Fig 3). As a result of a multivariate 
Table II. Multivariable analysis of prognostic factors among patients with an upper-lobe tumor $(n=78)$

\begin{tabular}{|c|c|c|c|c|c|}
\hline \multirow[b]{2}{*}{ Factors } & \multicolumn{2}{|c|}{ Characteristics } & \multirow[b]{2}{*}{ Risk ratio } & \multirow[b]{2}{*}{$95 \% C I$} & \multirow[b]{2}{*}{$\mathrm{P}$ value } \\
\hline & Unfavorable & Favorable & & & \\
\hline Sex & Male & Female & 1.570 & $0.701-3.514$ & .27 \\
\hline Age (y) & $<70$ & $70 \leq$ & 1.586 & $0.665-3.785$ & .30 \\
\hline Side of tumor & Right & Left & 1.154 & $0.604-2.205$ & .66 \\
\hline Histologic type & $\mathrm{AD}$ & SQ & 2.276 & $0.951-5.451$ & .064 \\
\hline Extent of involved nodes & Subcarinal $^{*}$ & Upper or aortic ${ }^{\dagger}$ & 2.840 & $1.158-6.966$ & .023 \\
\hline
\end{tabular}

$C I$, Confidence interval; $A D$, adenocarcinoma; $S Q$, squamous cell carcinoma.

*Involvement of subcarinal nodes.

'Involvement of only upper mediastinal or aortic nodes.

Table III. Multivariable analysis of prognostic factors among patients with a lower-lobe tumor $(n=47)$

\begin{tabular}{|c|c|c|c|c|c|}
\hline \multirow[b]{2}{*}{ Factors } & \multicolumn{2}{|c|}{ Characteristics } & \multirow[b]{2}{*}{ Risk ratio } & \multirow[b]{2}{*}{$95 \% C I$} & \multirow[b]{2}{*}{$\mathrm{P}$ value } \\
\hline & Unfavorable & Favorable & & & \\
\hline Sex & Female & Male & 1.191 & $0.495-2.864$ & .70 \\
\hline Age (y) & $70 \leq$ & $<70$ & 1.084 & $0.481-2.440$ & .85 \\
\hline Side of tumor & Left & Right & 1.492 & $0.690-3.230$ & .31 \\
\hline Histologic type & SQ & $\mathrm{AD}$ & 2.053 & $0.807-5.221$ & .13 \\
\hline Extent of involved nodes & Upper $^{*}$ & Lower $^{\dagger}$ & 2.358 & $1.022-5.439$ & .044 \\
\hline
\end{tabular}

$C I$, Confidence interval; $A D$, adenocarcinoma; $S Q$, squamous cell carcinoma.

*Involvement of upper mediastinal nodes.

Involvement of only lower mediastinal nodes.

Table IV. Multivariable analysis of prognostic factors among patients with a left upper-lobe tumor $(n=30)$

\begin{tabular}{lllccc}
\hline & \multicolumn{2}{c}{ Characteristics } & & & \\
\cline { 2 - 3 } Factors & Unfavorable & Favorable & Risk ratio & $95 \%$ CI & P value \\
\hline Sex & Male & Female & 2.409 & $0.595-9.752$ & .22 \\
Age (y) & $70 \leq$ & $<70$ & 1.481 & $0.082-26.693$ & .79 \\
Histologic type & AD & SQ & 4.858 & $0.268-88.052$ & .28 \\
Extent of involved nodes & Upper or lower ${ }^{*}$ & Aortic $^{\dagger}$ & 3.923 & $1.022-15.061$ & .046 \\
\hline
\end{tabular}

$C I$, Confidence interval; $A D$, adenocarcinoma; $S Q$, squamous cell carcinoma.

*Involvement of upper or lower mediastinal nodes.

'Involvement of only aortic nodes.

analysis among patients with a lower-lobe tumor (Table III), involvement of upper mediastinal nodes was identified to be an independent prognostic factor $(P=.044)$. Furthermore, patients with involvement of the aortic nodes alone from left upper-lobe tumors $(n=12)$ had a significantly better survival than those patients with metastasis to the upper or lower mediastinum beyond the aortic region $(\mathrm{n}=18 ; P=.044)$. The 5-year survival for these patients was $57 \%$ and $36 \%$, respectively (Fig 4). According to a multivariate analysis among patients with a left upper-lobe tumor (Table IV), involvement of upper or lower mediastinal nodes over aortic nodes was an independent prognostic factor $(P=.046)$. We also evaluated the effect of the number of stations of involved N2 lymph nodes on patients' survival. Patients with involvement of the single station $(n=84)$ had a significantly better survival than those patients with involvement of the multiple stations $(\mathrm{n}=57 ; P=.0001)$. The 5-year survival for these patients was 39\% and $11 \%$, respectively.

\section{Discussion}

The presence of mediastinal lymph node metastases in patients with lung cancer is a significant prognostic factor and may profoundly influence therapeutic decisions. The actuarial 5-year survival of patients with N2 non-small cell lung cancer having complete resection reported in the literature vary between $19.2 \%$ and 
$30 \% .{ }^{10-13}$ However, selection of patients and methods for reporting survival figures vary widely, thereby making comparisons between reported series difficult, if not impossible. It must be kept in mind that this series included both macroscopically apparent N2 disease and microscopic N2 disease but excluded incomplete resection. The study was retrospective analysis, but the number of missing data was too small; follow-up was obtained in all patients. Because we always keep lungsaving procedures in mind, ${ }^{8}$ pneumonectomy was performed infrequently and much less than sleeve lobectomy. In consequence, we had fewer postoperative complications such as pneumonia, pulmonary infarction, or pulmonary edema; and curative resection could be done with low operative mortality rates. Because we always perform routine systematic dissection of all the hilar and mediastinal nodes, we have many patients who were sliding from advanced N1 disease to early $\mathrm{N} 2$ disease at postoperative pathologic examination; that is, they had no macroscopically apparent N2 disease but microscopic N2 disease, and we had more patients with single station of involved N2 nodes than those with multiple stations of involved $\mathrm{N} 2$ nodes. In our series, therefore, $\mathrm{N} 2$ disease could be considered to achieve relatively good survival.

There have been some reports that have shown that patients with involvement of multiple N2 stations have a worse prognosis than those patients with involvement of only a single N2 station. ${ }^{13,14}$ These reports were compatible with our present study. However, the station of mediastinal lymph node metastases in relation to the location of the primary tumor has not been considered a prognostic indicator for survival in most publications. Also, the results on the importance of the involved station are conflicting in the literature. A few reports ${ }^{11,15}$ found that the level of the nodal station involved had only a minor effect on the potential for long-term survival and that the survival differences between the various levels of involvement appeared not to be of statistical significance. Riquet and colleagues ${ }^{16}$ reported that the distribution of the metastatic mediastinal lymph nodes was not important for the prognosis.

Miller and colleagues ${ }^{14}$ revealed that the survival in patients with involvement of upper mediastinum was improved compared with those patients with involvement of the lower mediastinum, regardless of the location of the primary tumor. Kirsh and Sloan ${ }^{17}$ reported better survival for patients with metastases in the upper mediastinum alone. This result was in agreement with ours in case of upper-lobe tumors.

Naruke and colleagues ${ }^{3}$ reported the survival of patients with subcarinal node involvement to be $9.1 \%$, as opposed to a $29 \%$ 5-year survival for patients with N2 disease without involvement of the node. In addition, Patterson and colleagues ${ }^{1}$ and Kirsh and Sloan ${ }^{17}$ reported a poor survival in patients with subcarinal involvement. We speculated that subcarinal nodes were significant as a cross-road where lymphatic channels from the various organs in the thorax meet directly or by means of lymphoid relays. ${ }^{18}$ Our own studies would confirm the importance of the subcarinal nodes and the poor prognostic implications when they are involved by upper-lobe cancer. This may have been because nodal involvement of subcarina tends to be more widely scattered. Nohl ${ }^{19}$ stated that, in upper-lobe cancers, subcarinal lymph node metastases usually occurred secondary to involvement of nodes around the main bronchus and noted that subcarinal involvement was infrequent. From these results, involvement of subcarinal lymph nodes from upper-lobe cancer is considered as more advanced disease.

Patterson and colleagues ${ }^{1}$ reported that patients with metastasis to subaortic lymph nodes alone had a comparatively good prognosis after complete resection and a 5-year survival of $42 \%$. Martini and Flehinger ${ }^{11}$ demonstrated a 35\% 5-year survival rate in patients with similar nodal involvement. In the present study, patients with involvement of only the aortic nodes from left upper-lobe tumors had a significantly better survival than those patients with metastasis to the upper or lower mediastinum. The subaortic nodes constitute an important pathway of lymph drainage for left upper lobe and may be equivalent to the hilar lymph nodes, unlike the other mediastinal lymph nodes. In contrast, Miller and colleagues ${ }^{14}$ found no difference in 5-year survival between patients with positive disease and negative disease in aortic nodes.

We regarded the location of the primary tumor, which was not under consideration in most of the past literature, very important in analyzing the relationship between the level of involved nodes and the prognosis.

Vansteenkiste and colleagues ${ }^{20}$ found that right upperand middle-lobe tumors had pathways of lymphatic metastases to the right upper-mediastinal nodes, right lower-lobe tumors to the lower ones, and left upper-lobe tumors to the aortic ones. These findings were compatible with our preceding study ${ }^{18} \mathrm{~A}$ usual pattern of lymphatic spread not following the findings mentioned earlier was considered a poor prognostic sign (eg, there were no 3-year survivors in patients with metastases to subcarinal nodes from an upper-lobe tumor).

From the results of the present study, it appears that the relationship between the station of mediastinal lymph node metastases and the location of the primary 
tumor is important when planning therapy for patients with N2 non-small cell lung cancer. When metastasis limited to upper mediastinal or aortic nodes from upper-lobe tumor, to lower mediastinal nodes from lower-lobe tumor, or to aortic nodes from left upperlobe tumor, the patient should undergo as complete a resection as possible because acceptable survival can be expected after radical resection.

\section{REFERENCES}

1. Patterson GA, Piazza O, Pearson FG, Todd TR, Ginsberg RJ, Goldberg M, et al. Significance of metastatic disease in subaortic lymph nodes. Ann Thorac Surg 1987;43:155-9.

2. Daly BD, Mueller JD, Faling LJ, Diehl JT, Bankoff MS, Karp DD, et al. N2 lung cancer: outcome in patients with false-negative computerized tomographic scans of the chest. J Thorac Cardiovasc Surg 1993;105:904-11.

3. Naruke T, Suematsu K, Ishikawa S. Lymph node mapping and curability at various levels of metastasis in resected lung cancer. J Thorac Cardiovasc Surg 1978;76:832-9.

4. Martini N, Flehinger BJ, Zaman MB, Beattie EJ. Prospective study of 445 lung carcinoma with mediastinal lymph node metastases. J Thorac Cardiovasc Surg 1980;80:390-9.

5. Anonymous. World Health Organization histologic typing of lung tumours. 2nd ed. Am J Clin Pathol 1982;77:123-36.

6. Mountain CF. A new international staging system for lung cancer. Chest 1986;89:225S-33S.

7. Kaplan E, Meier P. Non-parametric estimation from incomplete observations. J Am Stat Assoc 1958;53:457-81.

8. Cox DW. Regression models and life tables. J R Stat Soc 1972; 34:187-220.

9. Okada M, Tsubota N, Yoshimura M, Miyamoto Y. Surgical approach for multiple primary lung carcinomas. J Thorac Cardiovasc Surg 1998;115:836-40.
10. Watanabe Y, Shimizu J, Oda M, Hayashi Y, Watanabe S, Tatsuzawa $Y$, et al. Aggressive surgical intervention in N2 non-small cell cancer of the lung. Ann Thorac Surg 1991;51:25361.

11. Martini N, Flehinger BJ. The role of surgery in N2 lung cancer. Surg Clin North Am 1987;67:1037-49.

12. Naruke T, Goya T, Tsuchiya R, Suemasu K. The importance of surgery to non-small cell carcinoma of lung with mediastinal lymph node metastasis. Ann Thorac Surg 1988;46:603-10.

13. Goldstraw P, Mannam GC, Kaplan DK, Michail P. Surgical management of non-small cell lung cancer with ipsilateral mediastinal node metastasis (N2 disease). J Thorac Cardiovasc Surg 1994;107:19-28.

14. Miller DL, McManus KG, Allen MS, Ilstrup DM, Deschamps C, Trastek VF, et al. Results of surgical resection in patients with N2 non-small cell lung cancer. Ann Thorac Surg 1994;57:1095101.

15. Thomas PH, Piantadosi S, Mountain CF. Should subcarinal lymph nodes be routinely examined in patients with non-small cell lung cancer? J Thorac Cardiovasc Surg 1988;95:883-7.

16. Riquet M, Manac'h D, Saab M, Le Pimpec-Barthes F, Dujon A, Debesse B. Factors determining survival in resected N2 lung cancer. Eur J Cardiothorac Surg 1995;9:300-4.

17. Kirsh M, Sloan H. Mediastinal metastases in bronchogenic carcinoma: influence of postoperative irradiation, cell type, and locations. Ann Thorac Surg 1982;33:459-6.

18. Okada M, Tsubota N, Yoshimura M, Miyamoto Y. Proposal for reasonable mediastinal lymphadenectomy in bronchogenic carcinomas: role of subcarinal node in selective dissection. J Thorac Cardiovasc Surg 1998;116:949-53.

19. Nohl HC. The spread of carcinoma of the bronchus. London: Lloyd-Luke Ltd; 1962. p. 17-44.

20. Vansteenkiste JF, Deleyn PR, Deneffe GJ, Stalpaert G, Nackaerts KL, Lerut TE, et al. Survival and prognostic factors in resected N2 non-small cell lung cancer: a study of 140 cases. Ann Thorac Surg 1997;63:1441-50.

\section{Online-www.aats.org}

Now you can get The Journal of Thoracic and Cardiovascular Surgery online. The Journal online brings you faster delivery time, easy searching of current and back issues, links to PubMed, AATS, WTSA and other important sites, and more. Visit the Journal online today. 